\title{
COMBAT PSYCHIATRY AND PREVENTIVE ASPECTS OF MENTAL HEALTH*
}

\author{
Lieutenant-Colonel R. J. BELAS, T.D., M.B., M.R.C.Psych., D.P.M., R.A.M.C. \\ British Military Hospital, Singapore †
}

SUMMARY : A brief review is made of combat psychiatry during the period from World War 1 to the War in Viet-Nam, with emphasis on the preventive aspects.

Cases of combat exhaustion are considered in more detail and their various managements in Viet-Nam by the United States and Australian Forces are presented.

\section{Introduction}

Apart from the most unpleasant situation which currently exists in Northern Ireland, the United Kingdom has not been in military conflict since the emergency in the South Arabian Peninsula four years ago, when the withdrawal from Aden, which achieved independence, was carried out in the face of armed resistance. Nevertheless, since the end of World War II in 1945 the British Army has been in action in no less than nine campaigns of varying magnitude.

\begin{abstract}
Historical
Recognition of the problem

Before World War I the presence of psychiatric problems can be recognised in the many cases discharged from the Army with the diagnosis of "Shell-shock". In the post-war period it was noted that many thousands of such cases had been admitted to British mental hospitals where many remained for a considerable time. In 1922 the Southborough Committee was set up in Great Britain to examine the relationships within the problem. The Committee findings led to the emphasis on selective procedures in preventing psychiatric break-down too easily under stress.
\end{abstract}

\section{Prevention and screening}

In World War II the psychiatric emphasis was on prevention rather than cure. This proved a tremendous stimulation to selective and screening procedures and as a result psychiatrists were appointed to cope with these problems. This, in theory, should eliminate or, at least, considerably reduce psychiatric casualties-but perhaps too much was expected of the personnel selectors and psychiatrists who have no efficient predictive tool for this purpose. However, in the United Kingdom approximately two per cent of all men medically examined were rejected on psychiatric grounds, but, in spite of this, thirty one per cent of all medical discharges were on psychiatric grounds. The United States figures are ten and forty five per cent respectively (Ahrenfeldt 1968). The reasons for these differences may well be due to different selection criteria, for example, from 1939 to 1941 the British system was far from efficient, without proper personnel selection procedures, and administrative discharges included psychopathic and chronic delinquents many of whom were psychiatric cases who should, or could, have been detected and rejected at intake by adequate psychiatric screening. It would appear, therefore,

* Now Military Hospital, Catterick.

$\dagger$ Based on a position paper presented to the South East Asia Treaty Organisation Medical Conference held in Bangkok in June 1971. 
that in Britain although the recommendations of the Southborough Committee were acknowledged they were not implemented early enough and the results were not as good as perhaps were expected.

\section{Forward and early treatment of psychiatric casualties}

It is, I think, a fairly well-established fact about war, as about many other things, that even lessons learned the hard way are so quickly forgotten. This retrograde amnesia applied no less to the United Kingdom Medical Services because it had been discovered in Word War I that forward and early treatment of psychiatric break-downs produced good results. Furthermore, wartime experience has also taught us that stress reactions, and neuroses generally, particularly those produced by battle, are affected adversely by hospitalisation. This does not mean they do not require treatment but that they require it away from the atmosphere of a hospital with its adverse psychological effect, which may only encourage patients to feel that they are severely ill; this leads to fixation of symptoms, a retardation of clinical improvement and it weakens their motivation to return to arduous and unpleasant duty.

However, having established the need for Army psychiatrists, it was not until the Burma campaign of 1942 that they were attached to British Divisions and this then considerably reduced psychiatric wastage. It is interesting to record that the United States War Department created the position of Divisional Psychiatrist in January 1918. In the campaign in North West Europe in 1944 to 1945 the British had Divisional Exhaustion centres functioning in all major battles. Also, in 1942 in the Western Desert, it is reported that during action in which the 9th Australian Division was involved a psychiatric First Aid Post was established in a Field Ambulance with a psychiatrist in charge. This proved successful in treating states of fear and very few psychiatric casualties had to be sent back to hospital, (MacCallum 1968). When Great Britain became involved in Korea, psychiatrists were sent to forward medical units immediately. The United States has an extremely efficient psychiatric service operating in Viet-Nam, and Johnson (1969) who was Psychiatric Consultant to the United States Army in Viet-Nam, in Table I illustrated the comparative findings regarding United States Army psychiatric casualties in World War II, Korea and Viet-Nam.

Table I

Comparison between United States psychiatric casualties in World War II, Korea and Viet-Nam

\begin{tabular}{|c|c|c|}
\hline Theatre & $\begin{array}{l}\text { Returned to Duty } \\
\text { Within Division }\end{array}$ & $\begin{array}{l}\text { Returned to Duty Somewhere } \\
\text { in Combat Theatre }\end{array}$ \\
\hline World War II & 60 per cent & 90 per cent \\
\hline Korea (1953) & 88 per cent & 97 per cent \\
\hline Viet-Nam & \multicolumn{2}{|c|}{$\left(----\frac{-}{\text { Retained in Viet-Nam }} 90\right.$ per cent $-----\rightarrow$} \\
\hline
\end{tabular}

This shows a decreased break-down rate. Johnson indicates that the psychiatric casualty rate in 1969 in Viet-Nam is only "slightly greater" than the customary rate in the Army of 1 to $2 / 1000$ per year. 
Berry (1969) compares the United States ratio of wounded in action to psychiatric casualties for World War II, Korea and Viet-Nam as detailed in Table II.

Table II

Ratio between United States wounded in action and psychiatric casualties in the Pacific for World War II, Korea and Viet-Nam

\begin{tabular}{l|c|c|c}
\hline \multicolumn{1}{c|}{ Casualty } & $\begin{array}{c}\text { In the Pacific for } \\
\text { World War II }\end{array}$ & Korea & Viet-Nam \\
\hline Wounded in action & 3 & 4 & 16 \\
\hline Psychiatric casualties & 2 & 1 & 1 \\
\hline
\end{tabular}

Johnson attributes the Viet-Nam lowered psychiatric rate to five factors (a) The one year tour-something finite. (b) Leadership and training. (c) Care of the individual, both from the medical and welfare points of view. (d) Conditions of combat-The general infrequency of exposure to long periods of defensive action and the pattern of successful short term offensive operations. The exception to this was during the siege of Khe San when the incidence of combat exhaustion rose, and (e) The army's mental health programme.

These are the main relevant points that Johnson highlights but other features that also could contribute to the lowered psychiatric rate will be apparent during the course of this paper.

Berry and Nelson (1969) are also of the opinion that another reason is the calibre of the personnel serving in Viet-Nam, for example, there seemed to be an increased percentage of entrants, at least in the United States Navy and Marine Corps, among High School graduates which Berry states is "always the most powerful predictor of successful military service".

To summarize so far, during the last fifty years or so there has been an increasing awareness of the importance of psychiatric battle casualties and attempts to deal with them have been by screening in the first instance, that is, prevention, and forward treatment as they occur. Now, what about the actual psychiatric battle casualty himself? Most combat psychiatric cases are caused by stress (Isolated, Repeated or Continuous).

Generally speaking, there are two main groups of psychiatric battle casualty: (1) Battle (Combat) Exhaustion. (2) Non-Specific Psychiatric Illnesses.

\section{Battle (combat) exhaustion}

This is regarded as being one of the unique phenomena of battle. It is essentially a functional break-down due directly to the conditions of combat and its incidence appears to be greater where battle stress is both severe and prolonged. It would seem that men are especially sensitive to battle stress where exposure is prolonged or it is repeated, and the effects appear to be cumulative. In the light of experience it is certain that modern mechanised warfare imposes on the individual a strain so great that those involved in actual fighting, however basically stable they may be, will ultimately break down in direct proportion to the intensity and duration of their exposure to the stress of battle. Thus; psychiatric casualties of the type described as "battle exhaustion" are as inevitable as gunshot or shrapnel wounds. 
During the Italian Campaign, in World War II, various estimates were made of British and American troop combat effectiveness in terms of the number of aggregate combat days a soldier could function for before break-down (Ahrenfeldt 1968). Figures of 15 to 400 days were produced, depending on the intensity of the battle, amount of rest, withdrawal from the front line; and other contingencies, which shows how unpredictable it was. Many of the line officers considered that a man reached the peak of his effectiveness in the first 90 days of combat, after which his efficiency began to fall off and most were ineffective after 140 to 180 days (10 combat days -17 calendar days in the Italian Campaign). It was considered that six months would be required for him to be an effective combat soldier once more. Swank and Marchand (1946) noted that, in the Normandy Campaign, from D-Day to the breakthrough, when the stress of combat was continuous and severe and rest was infrequent, and usually for no longer than one day, combat exhaustion occurred in United States infantrymen in from 15 to 50 days. This is represented in Figure 1.

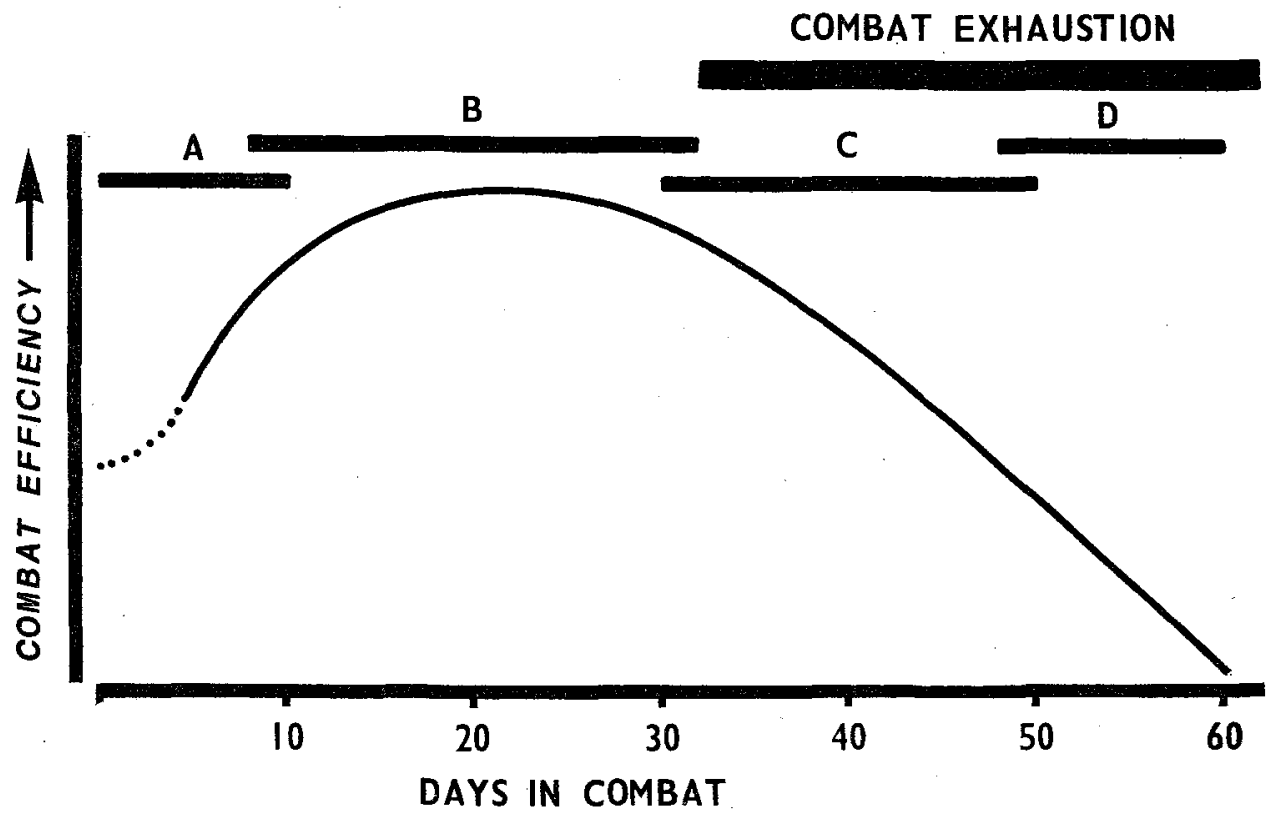

Key: A-Soldier becomes "battle-wise". B-Period of maximum efficiency. $C-$ Hyper-reactive stages. D-Emotional exhaustion stage.

(Illustrations Figs. 1 to 5 by courtesy of the University of Manchester Department of Medical Illustration, The Royal Infirmary, Manchester.)

Fig. 1. The relationship between days in combat and degree of combat efficiency.

Cases of combat exhaustion were seen during the battle of Britain. Collier (1966) reported in August 1940 the mounting losses then decreed that a pilot's expectation of life was no more than 87 flying hours, and many were so near collapse that their reactions were a long way off the medical board's touchstone: one-fifth of a second quicker than average. At Hawkinge, some pilots no sooner taxied in their planes than they slumped forward in the cockpit, often close to coma for 24 hours. One young Hurricane pilot was typical of many. After the day's eighth sortie he would stare at his log book, unable 
to record a thing except the times of take-off and landing. His mind blurred and seemed to take hold of nothing and all night long he writhed and dreamed of blazing planes.

Another factor which hastens break-downs under imposed stress is physical debility. Pavlov had noted this in experiments with dogs and Sargant (1969) also remarked about this in his dealings with civilians in the London Blitz during World War II. Some of these people with previously stable temperaments were unable to understand why they had developed severe anxieties about bombing when they had, hitherto, remained unaffected by it for weeks or months. In such cases it was frequently found that they had lost some 15 to $30 \mathrm{lbs}$ in weight before this ever increasing sensitivity to bombing had become noticeable.

Clutterbuck (1968) reports that the majority of communist guerillas captured or surrendered in Malaya were " dirty, unkempt and exhausted; they were undernourished, pale from lack of sunlight under the jungle canopy and weakened by festering sores from the bites of insects and leeches ". Thus it would seem therefore, that many of these men had broken down, or were on the verge of doing so. Perhaps an exception to this is Greville Wynne, the British spy, who only a few years ago fooled the Russians by not breaking down and confessing in spite of tremendous mental and physical pressures to do so, with associated great loss of weight. Wynne himself was convinced he would never break down because he was filled with such loathing and contempt for his captors that the more they tried to humiliate him the stronger became his mental resistance.

\section{Non-specific psychiatric illnesses}

These cases are usually not directly attributable to combat stress and they occur more frequently in the Line of Communication and Base areas. Examples are the neuroses in disordered personalities, the psychoses, alcohol and other drug problems. In relation to the latter it is relevant to mention that Colbach and Crowe (1970), Talbott and Teague (1969) discuss the use of marihuana by United States soldiers in Viet-Nam, and describe cases of marihuana psychosis.

The prognosis will depend on the diagnosis and the severity of the condition but on the whole is not as good as battle exhaustion cases who have been adequately treated.

\section{How can psychiatric battle casualíies be reduced?}

Firstly: By efficient selection and screening at entry or during initial training of the soldier.

Secondly: The removal of the battle experienced soldier who is nearing the stage of campaign exhaustion and who, it is considered, is showing the early signs of breakdown, for example, nervousness, tremor, irritability, lack of concentration, excessive smoking or drinking, insomnia, etc.

Thirdly: To improve "raw material" by thorough training based on sound psychological as well as military principles which includes such things as morale-building, understanding of purposes, efficient training and leadership, good welfare, adequate food, etc. Perhaps one of the greatest military psychologists is Field-Marshal Montgomery (1958) who demonstrated his understanding of these problems when he took command of the Eighth Army at El Alamein. Before the battle he explained to the troops exactly what he intended to do, promised he would do it, and mixed with them as much as possible. This raised their morale. He was very interested in their welfare and he stated 
“ a man's ordinary day to day life must be well organised. Thus, hard conditions imposed on him in training to inculcate discipline do not rule out the desirability of good living quarters; and in the line a soldier's morale will be much improved if the administrative arrangements are good and if he is assured of proper conditions with a reasonable amount of leisure and comfort when he leaves the Front. But here a warning must be given .... welfare by itself will not produce good morale because it is essentially soft and . . . morale cannot be good unless it contains a quality of hardness . . . men will endure great hardships if they know why and are convinced of the necessity. Men dumped in some out-of-the-way spot in the desert will complain less of boredom; because they have to shift for themselves, than those surrounded by a wide choice of amenities, and the troops will tolerate tremendous hardships if they know that their officers are enduring the same". Unver (1969) gives a very clear example of predisposing factors in psychiatric casualties and morale when he states that Turkish soldiers in the Dardanelles battle of World War I, and in the recent Cyprus disturbances, had no recorded psychiatric casualties, but there were some in Europe in World War II and in Korea. He explains this by stating "Turks are a highly patriotic people. In wars that have to do with their homeland no psychiatric casualties can happen . . . but in a war away from home the results never reach that standard". However, in Korea, Mitchell (1970) pays tribute to the fearlessness of the Turkish Brigade.

It is relevant to add here that during World War II many British Servicemen were chronically anxious about their families at home, who were themselves in danger from enemy bombing. Montgomery stressed the importance of mail and newspapers to alleviate this.

Fourthly: One must be continually on the qui vive for evidence of emotional problems which constantly occur and dealing with them as they arise. Many of these are welfare problems and their solution lies well within the province of all officers, not necessarily psychiatric, or even medical. Frequently all that is needed is sympathetic listening to the problem. However, sometimes advice is needed and occasionally a medical recommendation for a rest or change. It should be emphasised that these emotional problems may appear during the preparation period for battle when tension is building up.

\section{Treatment}

It is not the purpose of this paper to detail the treatment of all types of psychiatric casualty, particularly those conditions discussed under the heading of "Non-specific Psychiatric Illnesses ". Each case in this category must be dealt with on its merits by the medical officer involved. The treatment of cases of combat exhaustion, which respond so well to treatment, is considered in some detail. The essentials are that it must be Early and Forward. By Early is meant as soon as possible and certainly within a matter of hours of recognition. This means that treatment will frequently be carried out by Regimental or Field Ambulance medical officers and not by psychiatrists, who will be acting as advisers to the medical officers concerned in his area. This is best illustrated in Fig. 2 which is based on Stephens' (1971) experience in Viet-Nam with the Australian forces in 1968/69. Stephens stated:

(a) All casualty evacuation was performed by helicopter and this was rapid and efficient.

(b) Sedation treatment for psychiatric casualties was not given at Regimental level unless the patient was actively disturbed. 


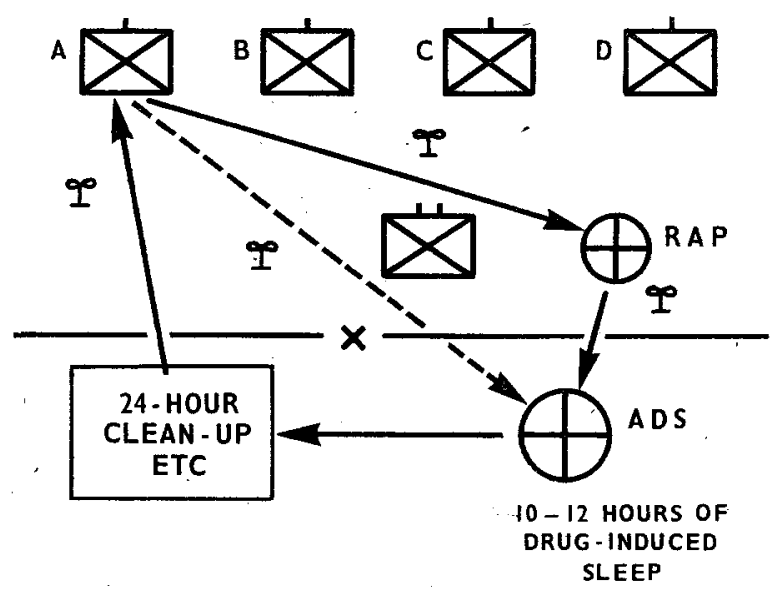

Fig. 2. Forward management of Australian cases of combat exhaustion in Viet-Nam in 1968/69 (Schematic)

Probably (b) depends upon (a), that is to say, if there had been delay in evacuation by air or if evacuation had to be performed by road, treatment would almost certainly have started earlier, in the forward area. The other point Stephens made was that he did not want a heavily sedated man in the forward area or Regimental Aid Post if there was any danger of enemy attack when, unsedated, he might have been useful in a defensive role. Delay was also reduced by evacuating a large proportion of casualties, particularly psychiatric, direct from the company to the Advanced Dressing Station following communication with the Regimental Medical Officer at his Regimental Aid Post at Battalion Headquarters. The management carried out by Stephens at the Advanced Dressing Station for combat exhaustion cases was as follows:

Intravenous barbiturate (Amylobarbitone Sodium)-up to milligrams 500, slowly, which gave some 10 to 12 hours sleep to the casualty. Following that, a 24 hour " clean up' period-wash, shave, a meal, mixing with others and elementary supportive psychotherapy, mainly in the form of simple reassurance, and then return to full duty in the line. Stephens claims that more than 90 per cent returned to duty on this regime, he only evacuated back one casualty from the Advanced Dressing Station and not one of these cases became a casualty a second time. In all he considers he dealt with approximately 70 combat exhaustion cases. Butcher (1971) mentions that he had several less severe cases of battle exhaustion which he dealt with at Battalion level by rest, simple reassurance and transient treatment with mild tranquillisers such as diazepam. Both Stephens and Butcher agree that parenteral barbiturates should never be used for battle exhaustion cases so far forward as the Regimental Aid Post and although this may agree with formal military medical principles it is probably a feature of this theatre of war. There may be a case for this form of treatment in the Battalion under different battle conditions, for example, fixed front warfare, and if the Regimental Aid Post is well situated for this treatment. If, however, it is considered at Field Ambulance level that the psychiatric casualty requires treatment further back, then the psychiatrist takes over at Divisional or Corps level, at the Field Hospital. There may well be a Divisional or Corps Exhaustion Centre attached. Also, it must be remembered, that owing to the terrain, or fighting, helicopter evacuation may of necessity or economy be direct to 
the Field or even Base Hospital, as happens frequently for casualties requiring early surgery Nasser (1971) states that at least during the last year in Viet-Nam, the Australians have modified their system of psychiatric casualty treatment and evacuation.

He himself as a Task Force psychiatrist visited Battalion Regimental Aid Posts twice weekly, or more frequently as required, to advise on treatment and disposal of psychiatric cases. Those that did not return to duty in the line would be evacuated not to the Field Ambulance but to the Field Hospital (Fig. 3).

It has not been possible to obtain direct access to the American psychiatric evacuation system in Viet-Nam, but Boyle (1971) stated that in 1967/68, when he served with the Australian Forces there, the United States battalions had a psychiatric social worker each of whom was in communication with the Divisional psychiatrist. These psychiatric social workers dealt with all psychiatric cases and, broadly speaking, their system was based on a 15 minute interview at Battalion level.

These 15 minute interviews were divided up into five minute periods, the first was sympathetic listening to the problem, the second, active supportive therapy in the form of advice in how to cope, raising of morale, "we are the finest Army, have the best weapons", etc., and the third five minutes the 'Boot' back into the Front Line (Fig. 4).

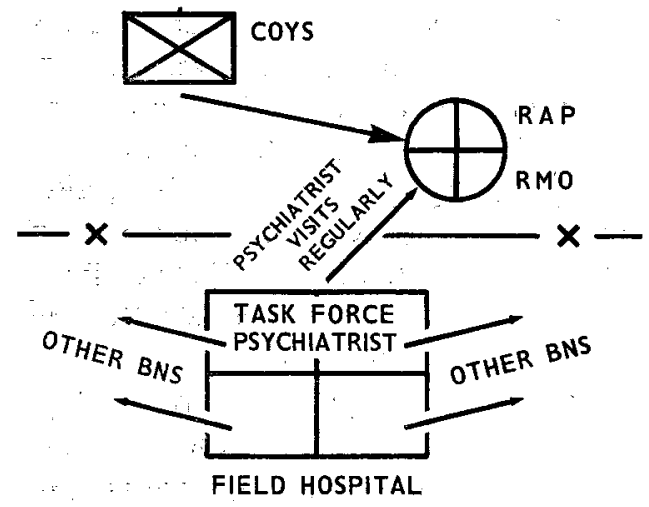

Fig. 3. Forward management of Australian cases of psychiatric casualties in Viet-Nam in 1971 (Schematic)

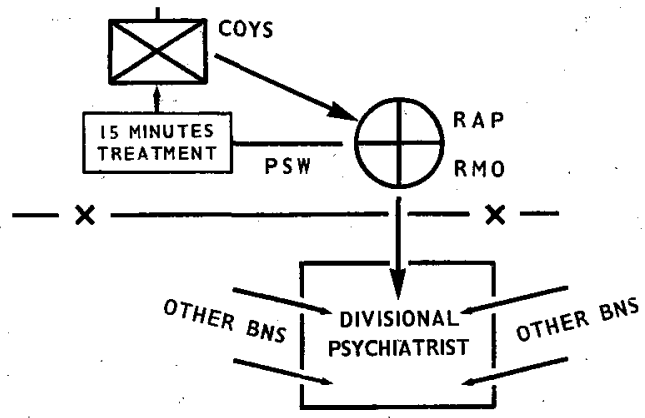

Fig. 4. Forward management of United States cases of psychiatric casualties in Viet-Nam in 1967/68 (Schematic)

Boyle stated that this rapid treatment had a high degree of success. If in difficulties the psychiatric social worker communicated with the psychiatrist who gave advice and evacuation, of course, was arranged in suitable cases. More recent evidence suggests that at present this system in the United States Army has been modified again in that the Regimental Medical Officer sees the patient first and decides the future of the individual psychiatric case (as he did originally) and the psychiatric social workers have been withdrawn from Battalion level (Fig. 5).

If the patient is evacuated further disposal is decided by psychiatric teams at Divisional level consisting of psychiatrists, psychologists and psychiatric social workers. In the British Army, following evacuation the psychiatrist continues treatment initiated forward and continuous narcosis, abreaction and psychotherapy are used, giving the soldier a chance to ventilate his problems and difficulties. Physical exercise, recreation, rehabilitation, etc., are carried out. If possible waiting periods in Rear Holding Units 


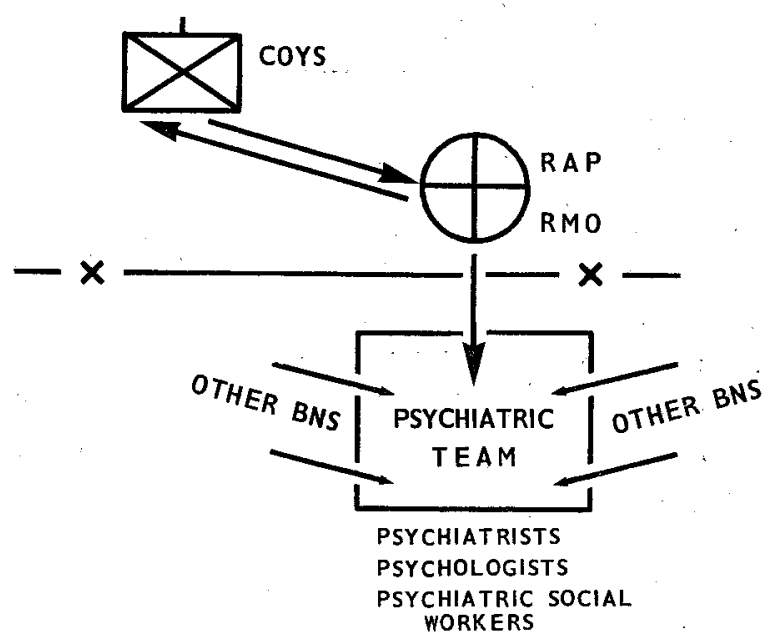

Fig. 5. Forward management of United States cases of psychiatric casualties in Viet-Nam in 1970/71 (Schematic)

are avoided as this will inevitably cause further deterioration. Cases who have responded to treatment should proceed direct to their future units immediately they are fit to do so.

For those psychiatric cases who have not responded so far, or who were severe enough in the first place, evacuation proceeds to the Base Hospital where further psychiatric therapy is undertaken. From here it may be necessary, in some cases, for example the psychoses, to evacuate out of the theatre of war. At the Base Hospital, however, all modern methods of treatment, including electro-convulsion therapy and drug therapy, are brought into use.

\section{Psychomatic disorders}

Mention should be made of the so-called psychomatic disorders; the boundaries of this group are not clearly defined. However, it is generally accepted that features of the peptic ulcer syndrome, migraine, certain skin disorders, colonic disorders, etc., come within this group. Casualties of this sort are usually dealt with by the general duty medical officers and physicians and they should bear in mind the psychological components of these conditions and to deal with them accordingly. These patients are frequently people of good personality whose break-down is indicated by physical disease. This is essentially an unconscious mechanism inculcated into them by group behaviour and moral standards, but their break-down in this way is, from the conscious point of view acceptable.

In Britain the attitude towards psychiatrists is coloured by suspicion and hollow humour in many circles. The feeling exists that psychiatric patients are "they" because "I am too strong, or too stable, for it to happen to me". In World War II the successful and rapid treatment of battle exhaustion cases impressed the Military, with a change of attitude towards psychiatry. The majority of soldiers in this category returned to the front line. This made the diagnosis of "battle exhaustion" more respectable and reduced the "moral stigma" previously associated with break-down. It also led commanders to understand that psychiatry was not just a means of evacuating a soldier 
without surgical evidence of trauma, but was acting in a positive role to try to keep up military strength.

It has already been indicated that battle exhaustion is proportional to the length and degree of combat stress. Murphy (1969) points out that a reliable pointer to the severity of battle stress is the number of wounded and thus the incidence of battle exhaustion parallels closely that of wounded in action. As Officer Commanding a Divisional exhaustion centre in Normandy in 1944 he experienced a time lag of 12 to 20 hours between the peak of the evacuation of wounded soldiers and those of psychiatric casualties and found this a very useful warning system.

It is appropriate here to mention that battle exhaustion may coexist with wounds or other injuries. Many wounded cases may later develop battle exhaustion when medical posts are under fire or subject to attack.

\section{What about the treatment of soldiers in battle by modern psychiatric drugs?}

Johnson (1969) stated that in Viet-Nam these drugs were widely used by medical officers not only in the treatment of battle casualties, but with combatant and support troops. Apparently these drugs were often used for emotional conditions, even when the cause was not immediately obvious. It was difficult to assess the effect of these drugs in keeping down the incidence of psychiatric morbidity, but their undesirable effects must be considered in relationship to the efficient soldier. By this it is meant the reliability of such a man under the influence of an unknown quantity of, for example, one of the Benzodiazepines, acting on his hypothalamus in general and his limbic system in particular.

As stated at the beginning of this paper, we, in Britain, are not currently engaged in combat, except for the present situation in Northern Ireland. Here casualties are occurring, not on a large scale, but at present with some degree of regularity. The author had the privilege recently of discussing the situation with a senior officer who served there. This man was battlewise, having served as an infantry officer in Korea and Malaya and was an excellent example of a courageous man. He stated that he had never been so frightened as when he stood in a Belfast street between two rival factions who were hurling insults, stones and bottles at one another, with the possibility of petrol bombs being thrown and bullets fired. To quote him " I am trained to fight and this is acceptable when I know who my enemy is, but when for political reasons, one cannot fight back, an impossible situation is created". This leads to questioning of purpose, indecision and consequent lowering of morale. This, it is suggested would increase the liability to psychiatric casualties, although so far it has not been possible to produce figures to support this theory. Be that as it may, there are approximately 10,000 British troops at present serving in Northern Ireland (March 1971) and a large number are rotating through.

\section{The future}

And so, what of the future of combat psychiatry? Brief attempt has been made to consider the experience of large, conventional battles in the two World Wars, supplemented by limited war as seen in Korea and Viet-Nam, to touch on emergencies such as Malaya, Borneo and Aden, and to mention Northern Ireland as again a slightly different issue. These have all given the psychiatric service considerable experience, and 
have confirmed the need for flexibility in planning, and understanding plus co-operation with the non-medical Services. From the psychiatric point of view this can only be done by ensuring that all Service psychiatrists have adequate knowledge and experience with general Service doctoring, and contact with psychologically normal people. There can never be enough of this experience for any doctor who wishes to understand, treat, and give advice on psychological problems.

\section{Acknowledgements}

I would like to thank Professor J. N. Walton, T.D., Dean of Medicine, University of Newcastle-on-Tyne, and Lieutenant-Colonel J. D. Cormack, R.A.M.C. Consultant in Army Medicine for their helpful advice in the preparation of this paper; to WO II J. Harley, R.A.M.C. for reproducing the tables and figures; and to Mrs. Jeanne Hon for typing the manuscript. 